\title{
BIM 技术在建筑工程机电安装施工中的应用
}

\author{
李树雄 \\ 昆明都市卫士信息技术有限公司 \\ DOI:10.32629/btr.v2i3.1913
}

[摘 要] 如今 BIM 技术凭借其诸多优势,被拓展应用到机电安装施工领域,并取得了良好成效。基于此, 本文结合工程实例, 围 绕建筑信息模型在机电安装施工中的实践应用展开探讨,旨在强化建筑机电工程施工质量,保证建筑性能安全。

[关键词] BIM 技术; 机电安装施工; 性能安全

当下, 中央空调、消防系统与安防系统的大范围应用, 在一定程度上增大了机电安装施工的难度系数, 为此, 加大 BIM 技术的应用投入, 有利于提高建筑机电安装的施工质量, 保证建筑性能安全。

\section{1 建筑信息模型技术的发展背景与实践应用}

1.1 BIM 技术的核心理念

BIM 技术是指在开放化的工业标准下, 以三维数字技术 为基础, 整合工程项目各类相关信息, 构建虚拟化的立体工 程模型, 并为模型提供完整的信息库。该数据库不仅涵盖整 个工程所需的各类构件的物质属性信息、几何信息与状态信 息, 还包括非构件的空间状态信息与运动行为信息, 实现对 工程项目实体与功能特性的数字化表达。

1.2 建筑信息模型技术的发展背景简介

传统建筑工程设计主要采用 Auto CAD 等专业计算机辅 助设计软件进行二维空间设计, 然而, 这种设计模式与人工 绘图存在相似之处, 单纯依赖于设计软件提高绘图效率与精 确性, 没有实质性突破。另外, 尽管工程设计师可以利用专业 设计软件制作效果图, 用于完善设计细节, 客观审视设计成 果, 但此类三维立体模型并未集成工程建设所需的材料与构 件的基本信息, 这使得效果图存在一定的局限性。

再者, 传统设计软件无法独立分解平面、立面与剖面, 导致局部设计与整体设计存在矛盾冲突, 影响了工程设计的 精确性。针对上述这些突出性问题, 应用 BIM 技术, 可以为设 计人员提供可靠的解决方案, 构建完整的三维立体建筑信息 模型, 以完善工程设计的集成化与信息化水平。

1.3 BIM 技术在机电工程中的实践应用

建筑信息模型技术具有碰撞检查、动态模拟施工与统计 工程量等基本功能, 可以全方位动态指导整个建筑机电安装 施工流程, 优化配置施工材料, 从而提高施工效率, 压缩成本, 缩短工期。

在建筑机电安装施工过程中, 利用建筑信息模型技术, 依托专业设计软件, 构建三维立体空间模型, 可对各类专业 机电管线进行综合碰撞检查, 从而优化管线设计, 保证系统 运行安全性。

在机电安装施工环节, 利用建筑信息模型技术, 可动态 模拟施工现场管理, 简化工作流程, 优化施工资源配置, 并且
对重难点工程进行预演模拟, 确保工程建设达到预期水平。

由于建筑信息模型技术与专业设计软件搭建的立体模 型涵盖多元化工程信息, 为此, 可准确统计工程量, 进而为工 程实践与成本控制提供必要的参考依据。

\section{BIM 技术在机电安装中的应用流程}

2.1 施工现场布置与前期准备

施工现场布置的主要内容有: 选择符合施工要求的运输 机械设备、优选现场运输路径、布置水、电与网络系统, 调 整施工材料存放场地。在此过程中, 应用 BIM 技术, 综合考量 技术标准规范、资源配置情况及勘察设计单位提供的环境信 息等。另外, 促进建筑信息模型技术与地理信息系统的有机 整合, 为构建三维立体空间模型提供完整的数据库, 最大限 度的提高信息整合与分析效率。施工技术人员也可以利用 BIM 技术, 综合分析施工环节存在的各方面制约因素, 以此维 护施工安全, 确保工程建设的有序运转。

\section{2 统计施工材料}

在构建立体信息模型的过程中, 应对各个内部元素设置 对应的参数, 减小施工方的工作压力, 同时结合工程概况, 统 计施工所需材料的种类与数量, 为执行工程管理工作提供必 要的参考依据。再者, 利用 BIM 技术, 可全方位控制各个机电 安装施工段的物资配置与使用情况, 加强物资供应的及时性 与充分性。不仅如此, 利用建筑信息模型技术, 还可制定完整 的库房管理方案, 动态控制物资的流转情况, 避免资源的过 度损耗。

\section{3 动态模拟现场施工}

施工模拟是以计算机技术为核心的虚拟施工模式, 也就 是利用建筑信息模型技术预演模拟施工流程。依托建筑信息 模型技术, 可快速获取施工所需原材料、机械设备与人力资 源等基础信息, 并以动画形式逐一呈现, 以便工程设计师与 管理人员及早发现工程存在的缺陷, 提高工程建设质量。

\section{4 动态监控施工进度}

在建筑机电设备安装过程中, 将建筑信息模型与施工进 度计划有机整合, 可构建涵盖时间信息的四维立体建筑空间 模型, 用于分析建筑机电安装工程中各类影响因素的内在关 系。四维立体建筑空间模型可全方位动态监控施工进度、机 械设备调度与资源配置, 且统计已完成的工程量, 帮助施工 
方调整进度。

2.5 控制施工成本

通过综合对比 BIM 技术构建的数据模型与实际工程, 有 助于控制施工成本, 明确劳务进度款与实际工程量的比例关 系, 对整个施工流程进行全方位动态监控。通过调整 BIM 数 据模型, 完善相关数据信息, 可确保模型与实际工程的相似 性, 并在竣工结算阶段, 将模型中的相关数据作为结算依据, 确保结算的准确性。

\section{6 施工安全管理与质量控制}

在传统的施工安全管理工作中, 存在的共性问题就是, 针对规模大、工序繁琐、时间跨度长的工程项目, 无法实现 完善的管理。在拓展应用建筑信息模型技术后, 可全方位动 态模拟整个施工流程, 优化施工方案, 进而为后续施工奠定 基础。

\section{BIM 技术的实践应用价值}

3.1 应用建筑信息模型技术动态模拟现场施工

Auto desk Navis works Simulate 软件内置多样化工 具, 具有完备的四维空间模拟功能与动画制作功能, 能够满 足用户预演模拟工程设计效果的需求, 以此全方位掌握整个 项目流程, 提高可预测性。在四维空间环境中, 仿真模拟施工 进度与施工流程, 通过可视化的方式综合分析项目运转情况, 消除影响施工进度的因素, 确保工程的有序运转。

此外, 利用 Auto desk Navis works Simulate 进行四维 仿真模拟的具体步骤如下: 综合参考工程立体模型的几何图 形与日期等基本信息, 调整施工工序; 从项目管理软件导入 各类参数信息, 以此为基准, 在工程项目模型与明细表间构 建动态链接; 设定预计时间与实际时间, 客观衡量可视化的 计划进度与实际进度的偏差。

为验证该软件实践应用的可行性, 可预先构建完整的仿 真模型, 并综合参考样板间的施工进度, 进行仿真分析。在此 过程中, 可通过调整工序衔接, 缩短工序持续时间, 缩短工期, 进而确保工程建设的有序运转。再者, 建筑信息模型技术可 通过可视化方式, 动态模拟施工程序与施工进度, 并针对重
难点工序进行预演模拟, 从而确保工序的高效流转衔接, 优 化施工技术方案, 最终提高资源整合效率, 做到工程经济效 益的最大化。

\section{2 应用建筑信息模型技术统计机电工程材料需求量}

建筑信息模型技术可综合分析管线敷设情况,动态模拟 现场施工, 同时, 可高效统计施工材料的配置与使用情况。 Auto desk Revit MEP 提供了多种明细表类别, 可分别统计 建筑结构、机械系统与电气工程系统所需材料的规格、型号 与数量等基本信息, 整合统计结果。在上述工程案例中, 利用 建筑信息技术, 统计了样板间工程所需的镀锌钢管的规格、 型号与数量, 为成本控制提供了必要的参考依据。

在建筑工程结构设计中, 高效整合应用建筑信息模型技 术, 可优化资源配置, 提高施工效率, 进而保证施工进度, 控 制成本损耗。与此同时, 其还可促进各工种的协调配合, 缩短 工期, 实现工程综合效益的最大化。从可持续发展角度来 看, BIM 技术的实践应用已不仅局限于工程设计与施工阶段, 其还逐步覆盖至整个建筑工程的维护与设施管理方面。

\section{4 结束语}

综上所述, 通过 BIM 技术等各类专业设计软件的拓展应 用, 有效促进了建筑信息技术与机电工程安装施工的有机整 合, 且通过碰撞检查、动态模拟施工、统计工程量等环节, 有效提高了机电工程施工质量, 维护了系统运行安全, 具有 极大的推广应用价值。

\section{[参考文献]}

[1]李敬波.建筑机电安装工程中 BIM 技术应用的研究 [J].住宅与房地产,2018,(36):69.

[2]唐及。解析 BIM 技术在机电安装工程中的应用研究 [J]。 时代农机,2018,45(11):219.

[3]杨祖华.BIM 技术在建筑机电安装工程中的应用分析 [J].中国信息化,2018,(12):47-48.

[4]叶长友.建筑机电安装工程的 BIM 技术应用[J].中国 战略新兴产业,2018,(24):87. 